\title{
Weather Conditions and the Bank Lending Channel: A GMM Approach from US Banking
}

\author{
Nicholas Apergis (Corresponding author) \\ Department of Banking and Financial Management, \\ University of Piraeus, \\ 80 Karaoli \& Dimitriou, \\ 18534 Piraeus, Greece, \\ Tel: +30-210-414-2429Ｅ-mail: napergis@unipi.gr \\ Panagiotis Artikis \\ Department of Business Administration, \\ University of Piraeus, \\ 80 Karaoli \& Dimitriou, \\ 18534 Piraeus, Greece, \\ Tel: +30-210-414-2200Ｅ-mail: partikis@unipi.gr
}

Received: March 1, 2012 Accepted: March 15, 2012 Published: April 15, 2012 doi:10.5430/ijfr.v3n2p17

URL: http://dx.doi.org/10.5430/ijfr.v3n2p17

\begin{abstract}
An issue that has not been dealt in the literature refers to the relationship between the bank lending channel and weather conditions. This paper provides empirical evidence, for the first time, that sheds new light into the dynamic interactions between weather and bank lending, using a panel data set that includes 69 banks operating in four different regions in the US, spanning the period 1994 to 2010. The methodology of panel GMM estimator, suggested in Arellano and Bond (1991), was used. The results indicate that weather characteristics have a statistically significant effect on the size of monetary policy transmission mechanism, which is also dependent on the size of banking institutions.
\end{abstract}

Keywords: Bank Lending Channel, Weather Conditions, Panel GMM, US Banking

\section{Introduction: The Bank Lending Channel and Mood}

Over the last decades, banks operate in an extremely competitive environment. According to standard financial intermediation, banks have multifold banking activities, such as lending credit and accepting deposits (Diamond, 1984; Gorton and Winton, 2003). In addition, Shleifer and Vishny (2010) argue that modern banks are also involved in other related activities, such as distributing securities, trading and borrowing money. These extra activities tend to impose additional constraints on how banking institutions are capable of allocating their capital resources into lending activities and trading activities. In an indirect fashion, such allocation decisions are related to the concept of investor sentiment, since they seem to affect stock returns. Therefore, changes in stock returns have an impact of banks' decision making related to their securitization decisions, and, thus, to their lending decisions, e.g. mortgage lending. Overall, say a downgrading (upgrading) trend in sentiments leads to lower returns (higher returns) and, in turn, to less (more) lending. Moreover, sentiments could reflect either biased expectations through the impact on the private information set or on bank manager's preferences, which both could have been affected by bank manager's mood, with the latter having received influence from changing weather conditions.

Baker and Wurgler (2004) and Shleifer and Vishny (2010) claim that all of these banking activities may result in mispriced loans and a behavior that generates systematic risk. These issues seem to be highly important in a financial crisis period, since the entire spectrum of activities that the bank is involved could block or weaken the lending mechanism and, thus, transferring the problem to the real economy. 
In spite of the immense interest in investigating the working of the bank lending channel, no study, so far, has provided any explicit comprehensive evidence on the impact of weather conditions on this channel. However, it has been shown extensively in the emotion psychology and behavioral finance literature that the decision making process and the risk taking attitudes of the banks' managers is highly affected by their mood and emotions, which, in turn, is affected by weather, situational and environmental factors. Therefore, we believe that weather induced bank managers' decisions could be reflected in the efficiency of this channel.

A potential mechanism that could be investigated is whether weather conditions tend to affect the actions of the decision maker in terms of risk perceptions, processing strategies, and attention and memory. Therefore, the motivation of this research attempt could be to answer the question about what are the effects of actions of the decision maker on the efficiency of the bank lending channel, while it implies an association between weather conditions and mood-influencing characteristics of bank institutions. In other words, the empirical results could suggest that weather-induced mood is a specific behavior, since weather influences mood, which, in turn, affects lending decision making.

Therefore, the goal of this empirical study is to fill this gap in the literature and to provide, for the first time, a comprehensive assessment of the association between the bank lending channel and weather conditions for the case of the U.S. banking industry, through the methodology of the panel General Method of Moments (GMM) analysis. We could also specify the hypothesis related to bank lending and explain the interaction between this lending mechanism and weather conditions, yielding:

Hypothesis: Good weather conditions, i.e. higher temperatures, lower rain and snow precipitation, and lower cloud cover, causing positive affects to managers, are positively related to the strength of the bank lending channel.

The potential explanation could be that managers, with negative affects induced by bad weather, perceive their current situation more negatively, while they believe that they are less likely to influence risky outcomes, which leads them to select less risky courses of action (Williams and Wong, 1999a), and, therefore, they are less likely to exhibit organizationally beneficial behavioral intentions (Williams and Wong, 1999b) and they move away from logical rules (Holland et al., 2010), resulting overall in the weakening of the lending channel.

Furthermore, weather induced mood is related to different information processing strategies (Forgas, 1995; Schwartz and Bless, 1991). Good weather inducing managers with positive affects, favor processing strategies that are simple and intuitive, use novel information, are characterized by non-conservative behavior, enhance exploratory and generative decisions and behaviors, reach decisions faster, are capable of returning to information already looked at and are in better position in evaluating external stimulus (Amabile et al., 2005; Bagozzi et al., 1999; Fiedler, 2001; Forgas, 2001; Fiedler, 2001; Isen et al., 1982). These types of decisions could enhance the efficiency of the bank lending mechanism. According to Isen and Baron (1991), good mood might prompt managers to consider more diverse and novel alternatives in strategic decision making. By contrast, bad weather that induces negative affects to executives and decision makers prompt careful, error avoiding and conservative behavior (Fiedler, 2001) and engage to a slower and less efficient decision process (Forgas, 1989), thus, producing neutral and typical decisions that on the long run will lead to a reduced efficiency of the lending mechanism.

According to Isen et al. (1982) and Isen and Means (1983), good mood, caused by good weather conditions and flexible decision taking that ignores information judged to be less important, leads to extreme results in the resolution of complex problems. Furthermore, Isen and Baron (1991) claim that processing strategies are affected by positive affects. Managers in weather induced good moods that use intuitive and creative processing strategies should produce more extreme performance. Bad weather induced mood managers that favor more careful and error avoiding strategies that make less use of available information in reaching their decisions (Webster et al., 1996), are expected to provide more strength to the lending mechanism.

Section 2 covers the literature relevant to the mood induced decisions along with that on the bank lending channel, while Section 3 presents the methodology of the bank lending channel. Section 4 reports the data set used in the analysis, while Section 5 presents the empirical findings. Finally, concluding remarks and policy implications are presented in Section 6.

\section{Literature Review}

\subsection{The Role of Mood in Decision Making}

The impact of strong emotions or mood on decision making and risk taking is well recognized in behavioral economics and finance (Isen and Baron, 1991; Orasanu, 1997; Peters and Slovic, 2000; Wilson, 2002). One of the fundamental questions closely related to the goal of our study, is whether mood affects the type of information individuals assess and, 
thus, their decision making and the adoption of successful strategies. The majority of theoretical description in the area of behavioral economics and finance account for mood affects on cognition in terms of certain basic and automatic principles, such as priming (Forgas and Bower, 1988) and accessibility (Wyer and Srull, 1986). In particular, mood theoretical approaches are described as memory models, which have to say a lot of information storage as well as the way information is actually used in decision making.

Empirical attempts show that the impact of mood on judgment and decision-making is generally pervasive, while they suggest that mood can affect human judgment and behavior, with decision makers being subject to various psychological and behavioral biases when making certain decisions, such as loss-aversion, overconfidence and mood fluctuations (Harlow and Brown, 1990; Odean, 1999; Isen, 2000). Damasio (1994) examines people with impaired ability to experience their emotions and shows that such emotions play a vital role in decision making. He also concludes that these people tend to make suboptimal decisions. When individuals form a new judgment they use their positive or negative mood as information, thus, misattributing it to the judgment target (Schwarz and Clore, 2007), while mood can color judgments through mood-congruency effects in attention and memory (Williams and Wong, 1999; Eich and Macauley, 2006). The rationale of this perspective is that decision makers that have good moods, when faced with a risky situation recall mainly the positively toned items, pay more attention on the positive items recalled and focus on the optimistic outcomes of the risky decision, whereas, decision makers with negative moods recall mainly the negative items and focus on the negative outcomes.

Within a perfect world, people are provided with enough information in reaching decisions based on logical rules. Adherence to such logical rules becomes critical in medicine, in psychology, in investments or in bank lending, i.e. decisions based on full available evidence, irrespective of personal preferences (O'Connor et al., 2003). But, in such a perfect world, a logical rule is mainly the exception and not the rule. This occurs because mood can influence the extent to which individuals stick to logical rules, since, they change the way individuals process information and act upon (Holland et al., 2010). Therefore, happy mood leads individuals to rely on their experiences, while sad mood leads individuals to suppress an experience-based response tendency and, thus, to move away from a logical rule and explore alternatives. According to Wright and Bower (1992), when a person has to cope with an uncertain future event, his mood may directly affect his judgment. They show that people in good mood are optimistic about future uncertain events and vice-versa. Bagozzi et al. (1999) also find that people in a positive-mood state are capable of evaluating external stimulus, such as life satisfaction, consumer products or even investment proposals, more positively than people in neutral- or negative-mood states. Loewenstein et al. (2001) provide theories linking mood and feelings to general decision-making. They develop the risk-as-feelings hypothesis, which incorporates the fact that decision makers are affected by the emotions they experience at the time of the decision. Emotional reactions to risky situations often diverge from cognitive assessments of risks and emotional reactions often drive decision making behavior.

Romer (2000), Hanock (2002) and Mehra and Sah (2002) establish the importance of emotions in economic decision-making. Forgas (1995) shows that mood strongly affects relatively abstract judgments about which people lack concrete information, such as investment appraisal decisions. Arkes et al. (1998) argue that emotions of individuals may influence assessments of risky decisions. They find that positive mood and emotions can foster both risk-prone behavior and risk-averse behavior, since when a positive-affect person faces a risk situation in which the potential loss is emphasized, the person demonstrates risk aversion, whereas, when the potential loss is minimized, then risk proneness is observed. If the decision maker perceives that there is a large likelihood of losses that he will avoid risk in an attempt to maintain his good feelings, he will seek risk in an attempt to benefit from gains without fearing the negative feelings associated with loosing (Willians and Wong, 1999).

All the above issues have substantial relevance for decision making and risk. People in negative moods may choose risky options to give themselves a chance of obtaining the positive outcome that could improve their state. If negative mood leads to higher analytic processing, then the choice of the safe option may be more likely to occur or it could be directed towards a detailed assessment of the costs and benefits of the risky situations. Leith and Baumeister (1996) find that a range of induced states increase the choice of risky options, while Pietromonaco and Rook (1987) find that mild depression reduces the selection of risky options.

A different source of empirical findings comes from research on human performance. In particular, studies in decisional conflict (Hockey, 1997) argue that a range of strategy changes under stress is associated with a reduction in the amount of information used in reaching decisions. Positive mood leads individuals to organize information into larger and more effective sets and to rely more on shortcuts in judgments and decision making. Individuals who feel good, reach decisions faster, while they are capable of returning to information already looked at. Such positive mood is affected by the social characteristics of the decisions to be made, by the personal relevance of the outcome expected, and by the 
quality of mood (Ross and Ellard, 1986). Forgas (1989) finds that sad mood is related to a complex type of behavior, i.e. it leads to slower and less efficient decision processes, but it triggers highly motivated and selective decision strategies and information preferences, while happy mood tends to lead to faster decision processes, while it makes people ignore information judged to be less important. Webster et al. (1996) show that fatigued and stressed individuals make less use of available information in reaching their decisions. Finally, Hockey et al. (2000) show that the degree of risk taken in every decision making is affected by variations in state mood, while the strongest effects on risk behavior occur with changes in stressed type of situations.

Williams and Wong (1999) test how mood influences managerial perceptions of risk and subsequent risk decisions. They examine whether managerial risk decisions are likely to be influenced by perceptions of the uncertainty associated with a given risk, the significance of the potential outcomes, the way in which the decision frame is perceived and whether the risks are perceived to be personally relevant. They show that managers in good moods are more likely to perceive situations in positive terms and their beliefs that they could control risky outcomes increases, while good mood increases the likelihood that managers who perceived situations as risky would choose riskier options.

Delgado-Garcia and De La Fuente-Sabate (2010) examine the influence of the affective traits of Spanish banks and savings banks CEO's on strategy and performance conformity. Affective traits refer to the long term tendencies of managers to experience positive or negative affects. They show that CEO's affective traits do influence their strategic choices. Specifically, negative affective traits lead to firm strategic conformity, whereas, positive affective traits are negatively related to strategic conformity. They also find that positive affects lead to innovative decisions and negative affects to more careful and conservative ones, a fact supported by various other studies, such as Isen (2000) and Amabile et al. (2005).

Lin et al. (2009) propose a microeconomic model of a banking firm by focusing on lending determination when sunshine induces upbeat moods. Specifically, they develop an option based model of bank behavior that integrates the weather induced managerial discretion with the bank lending considerations. Their results suggest that when a bank manager is in a good mood, his optimistic lending will result in lower default risk in equity returns. They argue that overoptimistic or more lending may cause lower risks.

Howarth and Hoffman (1984) find that performance in various mental and physical activities is correlated with humidity, sunlight and precipitation. These weather variables are usually grouped together, since they are a function of cloud cover and it is shown that good mood is associated in times of high amounts of sunlight and low cloudiness, and vice versa. According to Schwarz and Clore (1983), people tend to rate their life satisfactions much higher on sunny days than on cloudy or raining days. Rotton and Cohn (2000) conclude that high and low temperatures are related to aggression, while Nastos et al. (2006) show that geomagnetic storms are also associated with increased level of depression and anxiety.

\subsection{The Role of Weather Conditions in Finance}

In the financial economics literature an interesting area of research that has evolved investigates the possible impact of weather and environmental variables on investor behavior. The main argument of these studies is that weather influences the mood of investors, which in turn influences stock returns. These studies link the mood change to either risk aversion (Kamstra et. al., 2000, 2003; Cao and Wei, 2005; Floros, 2008), misattribution (Saunders, 1993; Dichev and James, 2001; Hirshleifer and Shumway, 2003; Dowling and Lucey, 2005, 2008) or change in the investors' view of the future (Keef and Roush, 1995; Chang et al., 2008). Studies in the area can be also classified into the ones that focus only on stock returns, studies that focus on stock return volatility and the ones that examine both stock returns, volatility and other market characteristics such as trading volume, liquidity etc. However, the empirical evidence is to some extent mixed.

Empirical findings have shown sunshine to be positively correlated with stock returns. Saunders (1993) shows that investors' mood is upbeat or optimistic on sunny days, which uplifts the stock market returns, and their pessimistic mood on cloudy days depresses the stock returns (Note 1). The empirical evidence of Hirshleifer and Shumway (2003) indicates that after controlling for sunshine other weather variables, such as rain and snow, become unrelated to stock returns (Note 2). Finally, the sunshine effect is persistent on stock returns even with the use of intraday data and after controlling for other adverse weather conditions, such as snowiness, raininess, temperature and wind speed (Chang et al., 2008) (Note 3).

Kamstra et al. (2000) provide evidence that daylight savings time (DST), which is responsible for sleep desynchronosis, causes market participants to suffer greater anxiety and prefer safer investments, pushing down stock prices following a DST shift (Note 4). Seasonal affective disorder (SAD), which is related to longer nights in the winter time causing depression to investors, is associated with lower stock returns (Kamstra et al., 2003) (Note 5). 
The psychological literature suggests that temperature is one of the three most important weather variables affecting people's mood, with the other two being sunshine and humidity (Howarth and Hoffman, 1984). Empirical findings (Cao and Wei, 2005; Floros, 2008) have shown an overall negative correlation between temperature and stock returns, while this relationship is slightly weaker in the summer than in the winter (Note 6 and 7). Furthermore, Kang et al. (2010) show that all three weather variables (temperature, sunshine, humidity), when examined together have an effect both on the returns and volatility of the stock market (Note 8).

Several psychological studies, e.g. Neal and Colledge (2000), Sands and Miller (1991), associate full moon phases with depressed mood, thus, many authors hypothesize that during full moon periods stocks are valued less and returns are lower. Dichev and Janes (2001) provide evidence that the difference in returns is large between different lunar phases and exceeds the market risk premium (Note 9). Furthermore, Yuan et al. (2006) indicate and that the return difference is not due to changes in stock market volatility, trading volumes, announcements of macroeconomic indicators, major global shocks and other calendar-related anomalies (Note 10).

The weather and environmental variables that have a strong relationship with stock market return volatility are SAD, temperature and cloudiness. Specifically, the relationship of SAD and volatility is more significant for countries furthest from the equator and small capitalization stocks (Dowling and Lucey, 2008) (Note 11, temperature is positively correlated to the perceived risk of investors (Kaplanski and Levy, 2009) (Note 12), and cloudiness is negatively associated with various measures of stock market volatility (Symeonides et al., 2010) (Note 13).

By contrast, there are a number of studies supporting that weather and environmental variables dot not affect stock returns. Kramer and Runde (1997) show that short-term stock returns are not affected by local weather (Note 14). Pardo and Valor (2003) indicate that, independently of the trading system, there is no influence of weather on stock prices (Note 15). Tufan and Hamarat (2004) also find that weather conditions do not have any effect on stock prices (Note 16). Goetzmann and Zhu (2005) find no difference in the propensity to buy or sell equities on cloudy days as opposed to sunny days (Note 17). Jacobsen and Marquering (2008) find a strong relationship with summer-winter seasonality in stock returns which, however, cannot be linked directly to weather induced mood changes of investors (Note 18). Yoon and Kang (2009) show that after the 1997 financial crisis the weather effect became insignificant (Note 19).

\subsection{The Bank Lending Channel}

The operation of the bank lending channel depends mostly on the supply of loans and how it is affected by other factors, which one of them could be weather characteristics. Specifically, a restrictive monetary policy leads to a decrease in bank reserves and deposits and, consequently, to a fall in loan supply. Therefore, business and consumers, who depend on bank lending, reduce their purchases of durable goods and purchases of capital for investment and therefore negatively affecting their output (Golodniuk, 2006). The opposite occurs in the case of an expansionary monetary policy. There are three necessary conditions for this channel to have economic power. First, firms should not be perfectly indifferent to the different types of finance. They should be dependent on bank loans and not be able to replace losses of bank loans -due to decreases in loan supply by the monetary authorities- with other types of finance (Oliner et al., 1995). If firms are indifferent between two types of financing, then the decrease in supply of loans does not affect them at all. Second, the central bank should be capable of affecting the supply of loans through the changes it imposes on the volume of reserves. For instance, in the case of a restrictive monetary policy, banks must not be capable of offsetting the decrease in funds from deposits by raising funds from other sources (Oliner et al., 1995). The third condition that should be satisfied for the presence of both the bank lending channel and the interest rate channel is that there must be some imperfections in the adjustment of the aggregate price level. Otherwise, the monetary policy would have no impact if prices could adjust by the same percentage every time money supply is changed (Golodniuk, 2006).

The bank lending channel literature has focused on investigating the presence of a channel in different economies or in a group of countries and, more specifically, it examines whether the effect on lending responses differs depending on the strength of a bank, which is also determined by variables, such as asset size, capitalization and liquidity. The empirical evidence supports the idea that well capitalized and liquid banks are less affected by monetary policy changes than banks that have low capital or liquidity ratios. As far as size is concerned, in most studies it appears to be irrelevant, that is small banks do not seem to be more sensitive to monetary policy shocks than large banks (Peek et al., 1995; Golodniuk, 2006). There are studies, though, which find that large banks in combination with high capitalization ratios are less responsive to monetary policy shocks (Kishan et al., 2000).

As far as the empirical procedure is concerned, there has been an important concern to overcome, which lies in the difficulty to identify whether the effects on output are due to shifts in loan demand or shifts in loan supply. The fact that both output and bank loans decrease after a negative change in monetary policy does not lead to the conclusion that this is due to changes in loan supply (Oliner et al., 1995; Brissimis et al., 2001) but may be the result of a shift in loan 
demand. For instance, a tight monetary policy leads to an increase in interest rates and consequently in higher costs, which does not favor investments and this in turn leads to a fall in loan demand and, therefore, in the volume of loans. To overcome this issue the literature has focused on the analysis of microeconomic data of firms and banks instead of the use of aggregate data (Kashyap et. al., 1993).

\section{Theoretical Methodology of Measuring the Bank Lending Channel}

This section presents the methodological approach followed to investigate the relationship of weather conditions with the presence of the bank lending channel. In particular, the analysis will examine the validity of the bank lending channel when certain weather conditions are not taken into account and when they are incorporated into the model, to examine whether they strengthen or weaken the operation of the channel. The baseline model that does not include such weather conditions takes the following form:

$$
\Delta \mathrm{lhL}_{\mathrm{kt}}=\alpha_{k}+\varphi_{k} \Delta \operatorname{lnL} \mathrm{ktt-1}_{j}+\sum_{j} \beta_{j} \Delta \operatorname{lng}_{\mathrm{kt}-\mathrm{j}}+\sum_{j} \delta_{j} \Delta \ln G D P_{t-j}+\sum_{j} \omega_{j} \pi_{t-j}+\varepsilon_{k t}
$$

with $\mathrm{k}=1, \ldots .8, \mathrm{t}=1, . \mathrm{T}$, where $\mathrm{k}$ denotes the bank, $\mathrm{L}_{\mathrm{kt}}$ denotes the loans of bank $\mathrm{k}$ at year $\mathrm{t}, \mathrm{r}_{\mathrm{kt}}$ denotes the short-term interest rate, $\mathrm{GDP}_{\mathrm{t}}$ denotes the GDP at year $\mathrm{t}, \pi_{\mathrm{t}}$ denotes the inflation at year $\mathrm{t}$, and $\varepsilon_{\mathrm{kt}}$ denotes the error term.

In equation (1), the growth rate of a country's lending $(\Delta \operatorname{lnL})$ is regressed on GDP growth rates $(\Delta \operatorname{lnGDP})$ and on inflation rates $(\pi)$ to control for loan demand changes due to macroeconomic activity. In other words, we have to isolate shifts in total loans caused by movements in loan demand. The introduction of these two variables is important because it isolates the monetary policy indicator, which is the short-term interest rate. More specifically, the growth rate of loans is regressed on the monetary policy growth rate. Additionally, we include lagged values of the dependent variable, because lagged loans affect current loans in an environment where a stable relationship is established between the bank and the customer. In other words, the bank acquires 'informational monopoly over a client' and hence it is extremely costly for a customer to change a bank, because the services of the new bank will be more expensive, since it needs to collect information about the new customer (Golodniuk, 2006). Monetary policy can also affect lending with lags, due to long-term contractual commitments. According to the theory of the bank lending channel, the coefficient of the interest rate must be negative to imply that loans fall after a monetary tightening.

In the second phase of the analysis, weather conditions are added and, hence, the equation yields the form:

$$
\Delta \mathrm{lhL}_{\mathrm{kt}}=\alpha_{k}+\varphi_{k} \Delta \operatorname{lnL}_{\mathrm{kt}-1}+\sum_{j} \beta_{j} \Delta \operatorname{lnr}_{\mathrm{kt}-\mathrm{j}}+\sum_{j} \delta_{j} \Delta \ln G D P_{t-j}+\sum_{j} \omega_{j} \pi_{t-j}+\theta W_{t}+\varepsilon_{k t}
$$

where $\mathrm{W}_{\mathrm{t}}$ represents weather conditions responding to temperature, rain precipitation, snow precipitation falling on the ground and cloud cover time. The difference between equation (1) and equation (2) is the presence of an environmental factor (i.e. weather) for the investigation of any potential effect on people's mood and ultimately on the bank lending channel. The model is estimated using the GMM estimator, suggested by Arellano and Bond (1991), while only statistically significant lags are used in the estimation.

\section{Data}

A sample of 69 commercial and savings banks in four different US regions, i.e. New York (9 banks), Chicago (45 banks), Los Angeles (12 banks) and Baton Rouge (3 banks) is used. The geographical distribution was chosen so that it captures all four different types of weather characteristics across the U.S. (East, North, West and South). Balance sheet and income statement annual data is used, which is obtained from the BankScope database spanning the period 1994 to 2010.

As far as the bank lending channel is concerned, total loans are used as the dependent variable. We also obtain short-term interest rates, which are used as a proxy for monetary policy, from the Datastream database. From the same source, GDP values for each country are obtained to control for demand effects that is to isolate changes in total loans which are caused by movements in loan demand. After reviewing the data for reporting errors and other inconsistencies, we obtain a panel dataset of 759 observations coming from our 69 banking sample. We examine only continuously operating banks to avoid any possible effect from entry and exit and, thus, we focus on the performance of healthy and surviving banking institutions. Our observations come from unconsolidated data, implying that we used only the variables for the U1 code (unconsolidated statement).

Weather data comes from AccuWeather.com site that provides detailed weather conditions for all major cities in the U.S. The measurements come as an average from different meteorological stations located in every city. In all of these stations, observations about the average temperature (in Fahrenheit degrees), the height of rain precipitation (in inches), the height of ground snow (in inches) and total cloud sky cover time (in minutes) for each day are obtained. Once all of 
these weather data is highly characterized by seasonality and to be certain that the empirical analysis is free of such problems, we deseasonalize our weather data set, thus, providing a conservative measure of the effect of such data. The deseasonalization was achieved by subtracting each year's mean from each daily mean. Annual weather data was obtained fby averaging daily weather observations. Finally, the software package RATS7 assisted the empirical analysis.

\section{Empirical Results}

The aim of this part of the analysis is to investigate whether the bank lending channel is present when certain weather conditions are not taken into account and when their presence is included into the model. After investigating the stationarity (unit root) properties of the variables under study and getting that all, but weather conditions, are characterized as I(1) variables (the results are available upon request), the GMM estimator, suggested by Arellano and Bond (1991), ensures both efficiency and consistency, while unit root testing (available upon request) ensures that the appropriate level of differentiation has been used. The advantages of the GMM estimator are that the estimations avoid endogeneity problems, while it avoids the correlation of fixed effects bank characteristics with the explanatory variables. The fixed effects are contained in the error term $\varepsilon_{\text {it }}$, which consists of the unobserved bank-specific effects and the observation-specific errors. It also avoids the problem of autocorrelation, because of the presence of the lagged dependent variable. The GMM dynamic panel-data estimator uses the following instruments: loans lagged one through four and the endogenous variables lagged one through five. The number of lagged instruments was chosen as to ensure the validity of the Sargan test. The results of the study concerning the bank lending channel in the case of US regions are summarized in Table 1. The results focus on both the bank lending coefficient and the weather characteristic coefficient.

$<$ Table 1 about here $>$

The results in the second column of Table 1 report the coefficients and standard errors of the variables in the model of equation (1). The coefficient of the monetary policy indicator (first column) indicates that the effects of the decisions of monetary policy on lending have the expected negative sign, indicating a reduction (increase) in loan growth as a result of an increase (decrease) in the interest rates and it is statistically significant at the $1 \%$ significance level. In particular, a one percent increase (decrease) in the short-term interest rate leads to a reduction (increase) in loan supply by 2.47 percent.

The next four columns report the coefficients and t-statistics of the variables in equation (2), the one that includes the term of the weather characteristic. Specifically, the third and fourth column report the results for the baseline model with temperature and rain precipitation, respectively. The coefficient of the monetary policy indicator remains negative as expected in both cases, however, it is greater than the coefficient in the baseline model and statistically significant, implying that the effect of the interest rate on loans is much stronger now. In terms of the two weather characteristics, temperature seems to positively affect and rain precipitation seems to negatively affect bank loan suppliers' mood, leading to a stronger reaction of the loan supply procedure. In particular, for the case of temperature the results show that a one percent increase (decrease) in temperature leads to a simultaneous increase (decrease) in loan supply by 6.12 percent, while for the case of rain precipitation the findings indicate that a one percent increase (decrease) in rain precipitation leads to a reduction (increase) in loan supply by 7.34 percent. The temperature and rain precipitation characteristics are statistically significant, indicating that these environmental effects have a statistically significant impact on the monetary transmission mechanism. Moreover, in both cases the explanatory power of the model has substantially increased from $55 \%$ to $74 \%$ and $75 \%$, respectively.

Finally, the remaining two columns report the results for the bank lending channel when snow precipitation and cloud cover time are included. The results display that the interest rate remains inversely related to total loans, with, once again, the coefficient remaining stronger than its counterpart in the baseline model. They are statistical significant in both cases at the $1 \%$ significance level. In terms of the two weather characteristics, there seems to be present a negative effect on loan supply. In particular, a one percent increase in snow precipitation and cloud cover time leads to a reduction in loan supply by 5.58 and 6.12 percent, respectively. In all cases, the Sargan test ensures the validity of instruments used, while the Arellano-Bond test for second order autocorrelation is accepted in each specification. The null hypothesis of the test $-A R(2)$ - is that the errors in the first difference regression exhibit no second order correlation. Therefore, the model seems correctly specified.

Overall, the empirical analysis displays that the four weather characteristics have a strong impact on the size of the bank lending transmission mechanism. This confirms the hypothesis posed in the introductory section and it could be explained, through behavioral terms, that these weather characteristics tend to fully transmit their influence either on loan suppliers' mood or banks sentiment. 


\subsection{Robustness Tests: The Bank Size Effect}

In this section, we will investigate whether the abovementioned weather characteristics are related to the size of the banking institutions included in the sample. This test is motivated by the empirical finding that larger banks have a higher percentage in loan supply; therefore, loan supply decisions are more likely to be affected by sentiments and mood to a larger extent than those concerning smaller banks. In other words, we expect the impact of weather effect to be more pronounced in the case of large banks. Banks were categorized by their size according to the median of their assets. The results for small and large banks are reported in Tables 2 and 3, respectively.

$<$ Tables 2 about here $>$

$<$ Table 3 about here $>$

In the model of Table 2, i.e. the results for the small banks, the signs of the coefficients are the same as in Table 1. In all weather cases, the coefficient of the weather effect remains strong and statistical significant; however, the coefficient of the monetary policy, though it remains negative and statistically significant, it displays a weaker monetary policy effect vis-à-vis the case where all banking institutions are included, indicating that the weather impact is weaker for the operation of the bank lending channel, since the percentage of loans is smaller for small banks.

By contrast, the results in Table 3, i.e. those for the large banks, show the monetary policy transmission is much stronger, not only vis-à-vis the small banks case, but also vis-à-vis the case where all banks are included in the sample, implying that the weather characteristics contribute stronger to changes in loan supply, considering that large banks bear the heaviest volume of loans.

Overall, this robustness test yields that the bank lending channel is weaker in the case of small banks and stronger in the case of large banks, thus, providing further evidence that mood or sentiment may affect the process of loan supply and, consequently, the power of the bank lending transmission mechanism. Once again, the statistical validity of the results both in Tables 2 and 3, i.e. the Sargan test and the AR(2) test, seems adequate.

\section{Concluding Remarks and Policy Implications}

This paper examined how the presence of the bank lending channel is affected by the weather effect, as it is measured by four different characteristics, i.e. temperature, rain precipitation, snow precipitation and cloud cover time. The results were obtained using the GMM estimator, 69 banks from four different US regions over the period 1994-2010. They reported the presence of the bank lending channel, both in the case when the weather effect was not included in the model for the estimation of the lending channel and in the case when that effect was included. The empirical findings indicated that in the second case, the strength of the channel becomes stronger. In other words, the weather effect makes stronger the bank lending channel, while the degree of strength depends on the size of the banks, i.e. large banks invigorate the lending channel, while small banks weaken it.

Moreover, the results indicate that the association between the weather effect and this type of the monetary policy transmission mechanism recommends that it might be valuable to go beyond a traditional banking model of bank profit maximization to explore certain banking operations, such as lending activities. This could be valid since moods and sentiments, affected by weather conditions, could affect the rationality of judgments and people's ability to process information (and given the severity of the information asymmetry problem in banking).

In addition, the results also show that rain precipitation has been the weather characteristic variable that has the largest impact on the supply of bank loans. Rain precipitation, along with temperature, has been identified in the psychological literature as an important factor affecting people's mood (Howarth and Hoffman, 1984). According to Cao and Wei (2005), the possible behavioral consequences of adverse temperature, rain precipitation and cloudiness can lead to either aggression (associated with risk-taking) and apathy (associated with risk-averting) and the net impact on managers risk taking depends on the trade-off between the two.

The results receive high importance due to their implications about the efficiency of the monetary policy to pump out liquidity into the real economy. Therefore, certain weather conditions could enhance the strength of the bank lending mechanism and, thus, to make stronger the capacity of the central bank, e.g. monetary policy, to stabilize the economy.

Further research on this field would include banking systems from different groups of countries, with banks from emerging economies or it would be challenging to investigate on an individual country analysis to figure out whether the weather effect differs, both in size and in statistical significance, across countries. 


\section{References}

Amabile, T. M., Barsade S. G., Mueller J. S. \& Staw B. M. (2005). Affect and creativity at work. Administrative Science Quarterly. 50, 367-403. http://dx.doi.org/10.2189/asqu.2005.50.3.367

Arellano, M. \& Bond, S. (1991). Some tests of specification for panel data: Monte Carlo evidence and an application to employment equations. Review of Economic Studies. 58, 277-297. http://dx.doi.org/10.2307/2297968

Arkes, H., Herren, L. T. \& Isen, A. (1988). The role of potential loss in the influence of affect on risk-taking behaviour. Organizational Behavior and Human Decision Making Processes. 42, 181-193. http://dx.doi.org/10.1016/0749-5978(88)90011-8

Bagozzi, R., Gopinath, M. \& Nyer, P. (1999). The role of emotions in marketing. Journal of the Academy of Marketing Science. 27, 184-206. http://dx.doi.org/10.1177/0092070399272005

Baker, M. \& Wrugler, J. (2004). A catering theory of dividends. Journal of Finance. 59, $1125-1165$. http://dx.doi.org/10.1111/j.1540-6261.2004.00658.x

Brissimis, S. N., Kamberoglou, N. C. \& Simigiannis, G. T. (2001). Is there a bank lending channel of monetary policy in Greece? Evidence from bank level data. European Central Bank, Working Paper Series, Working Paper No. 104.

Cao, M. \& Wei, J. (2005). Stock market returns: A note on temperature anomaly. Journal of Banking \& Finance. 29, 1559-1573. http://dx.doi.org/10.1016/j.jbankfin.2004.06.028

Chang, S. C., Chen, S. S., Chou, R. K. \& Lin, Y. H. (2008). Weather and intraday patterns in stock returns and trading activity. Journal of Banking \& Finance. 32, 1754-1766. http://dx.doi.org/10.1016/j.jbankfin.2007.12.007

Damasio, A. (1994). Descartes’ Error: Emotion, Reason, and the Human Brain. New York: Putnam.

Delgado-Garcia, J. B. \& De La Fuente-Sabate J. M. (2010). How do CEO emotions matter? Impact of CEO affective traits on strategic and performance conformity in the Spanish banking industry. Strategic Management Journal. 31 , $562-574$.

Diamond, D. (1984). Financial intermediation and delegated monitoring. Review of Economic Studies. 51, $393-414$. http://dx.doi.org/10.2307/2297430

Dichev, I. D. and Janes, T. D. (2001). Lunar cycle effects in stock returns. Working Paper, University of Michigan.

Dowling, M. \& Lucey, B. M. (2005). Weather, biorhythms, beliefs and stock returns-some preliminary Irish evidence. International Review of Financial Analysis. 14, 337-355. http://dx.doi.org/10.1016/j.irfa.2004.10.003

Dowling, M. \& Lucey, B.M. (2008). Robust global mood influences in equity pricing. Journal of Multinational Financial Management. 18, 145-164. http://dx.doi.org/10.1016/j.mulfin.2007.06.002

Eich, E. \& Macauley, D. (2006). Fundamental factors in mood-dependent memory. In J. P. Forgas (ed.), Feeling and Thinking. Cambridge, UK: Cambridge University Press.

Fiedler K. (2001). Toward an integrative account of affect and cognition phenomena using the BIAS computer algorithm. In Feeling and Thinking: The Role of Affect in Social Cognition. Forgas JP (ed). Cambridge University Press: Cambridge, UK.

Floros, C. (2008). Stock market returns and the temperature effect: new evidence from Europe. Applied Financial Economics Letters. 4, 461-467. http://dx.doi.org/10.1080/17446540801998585

Forgas, J. P. (1989). Mood effects on decision making strategies. Australian Journal of Psychology. $41,197-214$. http://dx.doi.org/10.1080/00049538908260083

Forgas, J. P. (1995). Mood and judgment: The Affect Infusion Model (AIM). Psychological Bulletin. 117, $39-66$. http://dx.doi.org/10.1037/0033-2909.117.1.39

Garrett, I., Kamstra, M. J. \& Kramer, L. A. (2005). Winter blues and time variation in the price of risk. Journal of Empirical Finance. 12, 291-316. http://dx.doi.org/10.1016/j.jempfin.2004.01.002

Goetzmann, W. N. \& Zhu, N. (2002). Rain or shine: where is the weather effect?. Yale ICF Working Paper, No. 02-27, Yale University.

Golodniuk, I. (2006). Evidence on the bank lending channel in Ukraine. Research in International Business and Finance. 20, 180-199. http://dx.doi.org/10.1016/j.ribaf.2005.09.007 
Gorton, G. \& Winton, A. (2003). Financial intermediation. In G. Constantinides, M. Harris, and R. Stulz (eds.), Handbook of the Economics of Finance, Amsterdam: North Holland.

Hanock, Y. (2002). Neither an angel nor an ant: Emotion as an aid to bounded rationality. Journal of Economic Psychology. 23, 1-25. http://dx.doi.org/10.1016/S0167-4870(01)00065-4

Harlow, W. V. \& Brown, K. C. (1990). Understanding and assessing financial risk tolerance: a biological perspective. Financial Analysts Journal. 46, 50-62. http://dx.doi.org/10.2469/faj.v46.n6.50

Hirshleifer, D. \& Shumway, T. (2003). Good day sunshine: Stock returns and the weather. Journal of Finance. 58, 1009-1032. http://dx.doi.org/10.1111/1540-6261.00556

Hockey, G. R. J. (1997). Compensatory control in the regulation of human performance under stress and high workload: A cognitive energetical framework. Biological Psychology. 45, 73-93. http://dx.doi.org/10.1016/S0301-0511(96)05223-4

Hockey, G. R. J., Maule, A. J., Clough, P. J. \& Bdzola, L. (2000). Effects of negative mood states on risk in everyday decision making. Cognition and Emotion. 14, 823-855. http://dx.doi.org/10.1080/02699930050156654

Holland, R. W., De Vries, M., Corneille, O., Rondeel, E. \& Witteman, C. L. M. (2010). Mood effects on dominated choices: Positive mood induces departures from logical rules. Journal of Behavioral Decision Making. www.Wileyonlinelibrary.com/doi/10.1002/bdm.716.

Hong, D. \& Kumar, A. (2002). What induces noise trading around public announcement events? Working Paper, Cornell University.

Howarth, E. \& Hoffman, M. S. (1984). A multidimensional approach to the relationship between mood and weather. British Journal of Psychology. 75, 15-23. http://dx.doi.org/10.1111/j.2044-8295.1984.tb02785.x

Isen, A, M \& Means, B. (1983). The influence of positive affect on decision-making strategy. Social Cognition. 2, 18-31. http://dx.doi.org/10.1521/soco.1983.2.1.18

Isen, A. M. (2000). Positive affect and decision making. In Handbook of Emotions. (2nd ed.), Lewis M, Haviland-Jones JM (eds). Guilford Press: New York.

Isen, A.M. \& Baron, R.A. (1991). Positive affect as a factor in organizational behavior. Research in Organizational Behavior. 13, 1-53.

Isen, A.M., Means, B., Patrick, R. \& Nowicki, G. P. (1982). Some factors influencing decision-making strategy and risk-taking. In Affect and Cognition. Clark, M,S, Fiske, S, (eds). Erlbaum: Hillsdale, NJ.

Jacobsen, B. \& Marquering, W. (2008). Is it the weather?. Journal of Banking \& Finance. 32, 526-540. http://dx.doi.org/10.1016/j.jbankfin.2007.08.004

Kamstra, M. J., Kramer, L. A. \& Levi, M. D. (2000). Losing sleep at the market: the daylight-savings anomaly. American Economic Review. 90, 1005-1011. http://dx.doi.org/10.1257/aer.90.4.1005

Kamstra, M. J., Kramer, L. A. \& Levi, M. D. (2003). Winter blues: a SAD stock market cycle. American Economic Review. 93, 324-333. http://dx.doi.org/10.1257/000282803321455322

Kaplanski, G. \& Levy, H. (2009). Seasonality in perceived risk: a sentiment effect. http://ssrn.com/abstract=1116180

Kashyap, A. K., Stein, J. C. \& Wilcox, D. W. (1993). Monetary policy and credit conditions: evidence from the composition of external finance. American Economic Review. 83, 78-98.

Keef, S. P. \& Khaled, M. S. (2011). Are investors moonstruck? Further international evidence on lunar phases and stock returns. Journal of Empirical Finance. 18, 56-63. http://dx.doi.org/10.1016/j.jempfin.2010.11.002

Keef, S. P. \& Roush, M. (2005). Influence of weather on New Zealand financial securities. Accounting and Finance. 45, 415-437. http://dx.doi.org/10.1111/j.1467-629x.2004.00135.x

Kishan, R. P. \& Opiela, T. P. (2000). Bank size, bank capital and the bank lending Channel. Journal of Money, Credit and Banking. 32, 121-141. http://dx.doi.org/10.2307/2601095

Kramer, W. \& Ralf, R. (1997). Stocks and the weather: an exercise in data mining or yet another capital market anomaly?. Empirical Economics. 22, 637-641. http://dx.doi.org/10.1007/BF01205784

Leith, K. P. \& Baumeister, R. F. (1996). Why do bad moods increase self-defeating behaviour? Emotion, risk and self-regulation. Journal of Personality and Social Psychology. 71, 1250-1267. http://dx.doi.org/10.1037/0022-3514.71.6.1250 
Lin, J. J., Lin, J. H. \& Jou, R. (2009). The effects of sunshine-induced mood on bank lending decisions and default risk: an option-pricing model. WSEAS Transactions on Information Science and Applications 6, 946-955.

Loewenstein, G. F., Weber, E. U., Hsee, C. K. \& Welch, N. (2001). Risk as feelings. Psychological Bulletin. 127, 267-286. http://dx.doi.org/10.1037/0033-2909.127.2.267

Mehra, R. \& Sah, R. (2002). Mood fluctuations, projection bias and volatility of equity prices. Journal of Economic Dynamics and Control. 26, 869-887. http://dx.doi.org/10.1016/S0165-1889(01)00035-5

Nastos, P., Paliatsos, A., Tritakis, V. \& Bergiannaki, A. (2006). Environmental discomfort and geomagnetic field influence on psychological mood in Athens, Greece. Indoor and Built Environment. 15, 365-372. http://dx.doi.org/10.1177/1420326X06067372

Neal, R.D. \& Colledge, M. (2000). The effect of the full moon on general practice consultation rates. Family Practice. 17, 472-474. http://dx.doi.org/10.1093/fampra/17.6.472

O'Connor, A. M., Legare, F. \& Stacey, D. (2003). Risk communication in practice: the contribution of decision aids. British Medical Journal. 327, 736-740. http://dx.doi.org/10.1136/bmj.327.7417.736

Odean, T. (1999). Do investors trade too much?. American Economic Review. 89, 1279- 1298. http://dx.doi.org/10.1257/aer.89.5.1279

Oliner, S. D. \& Rudenbusch, G. D. (1995). Is there a bank lending channel for monetary policy?. Federal Reserve Bank of San Francisco, Economic Review. 2, 1-22.

Orasanu, J. (1997). Stress and naturalistic decision making: strengthening the weak links. In R. Flin, E. Salas, M. Strub and L. Martin (eds.), Decision Making Under Stress. Aldershot, UK: Ashgate.

Pardo, A. \& Valor, E. (2003). Spanish stock returns: where is the weather effect?. European Financial Management. 9, 117-126. http://dx.doi.org/10.1111/1468-036X.00210

Peek, J. \& Rosengren, E. S. (1995). Bank lending and the transmission of monetary Policy. In Peek, J. and Rosengren, E. S. (Eds.), Is Bank Lending Important for the Transmission of Monetary Policy?, Federal Reserve Bank of Boston Conference Series, No 39, 47-68.

Peters, E. \& Slovic, P. (2000). The springs of action: affective and analytical information processing in choice. Personality and Social Psychology Bulletin. 26, 1465-1475. http://dx.doi.org/10.1177/01461672002612002

Pietromonaco, P. R. \& Book, K. S. (1987). Decision style in depression: the contribution of perceived risks versus benefits. Journal of Personality and Social Psychology. 52, 399-408. http://dx.doi.org/10.1037/0022-3514.52.2.399

Romer, P. M. (2000). Thinking and feeling. American Economic Review. 90, 439-443. http://dx.doi.org/10.1257/aer.90.2.439

Ross, M. \& Ellard, J. H. (1986). On winnowing: the impact of scarcity on allocators' evaluations of candidates for a $\begin{array}{llllll}\text { resource. Journal of Experimental Social } & \text { Psychology. } & \text { 22, } & \text { 374-388. }\end{array}$ http://dx.doi.org/10.1016/0022-1031(86)90021-1

Rotton, J. \& Cohn, E. (2000). Violence is a curvilinear function of temperature in Dallas: a replication. Journal of Personality and Social Psychology. 78, 1074-1081. http://dx.doi.org/10.1037/0022-3514.78.6.1074

Sanders, J.L. \& Brizzolara, M.S. (1982). Relationship between mood and weather. Journal of General Psychology. 107, 157-158. http://dx.doi.org/10.1080/00221309.1982.9709917

Sands, J. M. \& Miller, L. E. (1991). Effects of moon phase and other temporal variables on absenteeism. Psychological Reports. 69, 959- 962.

Saunders, E. M. J. (1993). Stock prices and wall street weather. American Economic Review. 83, 1337-1345.

Schwarz, N. \& Clore, G. L. (2007). Feelings and phenomenal experiences. In E. T. Higgins and A. Kruglanski (eds.), Social Psychology: Handbook of Basic Principles. (2nd Edition), New York: Guilford Press.

Shleifer, A. \& Vishny, R. W. (2010). Unstable banking. Journal of Financial Economics. 97, 306-318. http://dx.doi.org/10.1016/j.jfineco.2009.10.007

Symeonidis, L., Daskalakis, G. \& Markellos, R.N. (2010). Does the weather affect stock market volatility?. Finance Research Letters. 7, 214-223. http://dx.doi.org/10.1016/j.frl.2010.05.004

Tufan, E. \& Hamarat, B. (2004). Do cloudy days affect stock exchange returns?: evidence from Istanbul stock exchange. Journal of Naval Science and Engineering. 2, 117-126. 
Webster, D. M., Richter, L. \& Kruglanski, A. W. (1996). On learning to conclusions when feeling tired: Mental fatigue effects on impressional primacy. Journal of Experimental Social Psychology. 32, 181-195. http://dx.doi.org/10.1006/jesp.1996.0009

Williams, S.W. \& Wong T. S. (1999b). Mood and organisational citizenship behaviour: The effects of positive affect on employee organisational citizenship behaviour intentions. Journal of Psychology: Interdisciplinary and Applied. 133, 656-668. http://dx.doi.org/10.1080/00223989909599771

Williams, S.W. \& Wong, Y. (1999a). The effects of mood on managerial risk perceptions: exploring affect and the dimensions of risk. The Journal of Social Psychology. 139, 268-287. http://dx.doi.org/10.1080/00224549909598384

Wilson, T. D. (2002). Strangers to Ourselves: Discovering the Adaptive Unconscious, Cambridge, MA: Harvard University Press.

Wright, W. F. \& Bower, G. H. (1992). Mood effects on subjective probability assessment. Organizational Behavior and Human Decision Processes. 52, 276-291. http://dx.doi.org/10.1016/0749-5978(92)90039-A

Wyer, R. S. \& Srull, T. K. (1986). Human cognition and its social context. Journal of Personality and Social Psychology. 93, 322-359.

Yoon, S. M. \& Kang, S. H. (2009). Weather effects on returns: evidence from the Korean stock market. Physica A. 388, 682-690. http://dx.doi.org/10.1016/j.physa.2008.11.017

Yuan, K. \& Zhu, L. Z. Q. (2006). Are investors moonstruck? Lunar phases and stock returns. Journal of Empirical Finance. 13, 1-23. http://dx.doi.org/10.1016/j.jempfin.2005.06.001

Zhu, N. (2002). The local bias of individual investors. Working Paper, Yale School of Management.

\section{Notes}

Note 1. Saunders (1993) is the first to link investment behavior to weather conditions. He uses meteorological data from the City of New York and stock market data for the Dow Jones Industrial Average (DJIA) and the NYSE/AMEX index from 1927 to 1989. The weather variable that he uses is the cloud cover, because it is highly influential on mood. The methodology, firstly, pairs data percentage cloud cover with data on stock price indices returns on a daily basis. Then the mean percentage daily change and the frequency of positive daily change are calculated for each of the indices. Secondly, the daily index return is regressed against a month dummy, a day dummy, a cloud cover variable and a lagged return variable. The day and moth dummies control for possible seasonal anomalies and the lagged return accounts for non-synchronous trading effects. His empirical evidence suggests that less cloud cover is associated with higher returns and the return difference between the cloudiest days and the least cloudy days is statistically significant.

Note 2. Hirshleifer and Shumway (2003) examine the relationship between cloud cover in the city of a country's leading stock exchange and daily market index returns across 26 stock markets around the globe for the period of 1982-1997. They calculate the average cloudiness value for each week of the year in each city and deseasonalize by subtracting each week's mean cloudiness from each daily mean. Their methodology involves univariate regressions of returns against the cloudiness measure for each city, logit models of maximum likelihood, pooled regressions with data from all cities and a city-specific fixed effects model with panel corrected standard errors. Their empirical evidence shows that sunshine is highly correlated with stock returns, in line with Saunders (1993).

Note 3. Chang et al. (2008), instead of using daily returns as previous studies, focus on the relation between cloud cover and intraday returns and trading patterns of New York Stock Exchange stocks from 1994 to 2004. Trading patterns are captured by trading volume, bid-ask spread, quoted depth, return volatility and order imbalance. The volatility estimation based on the range of the intraday prices and on the basis of the standard deviation of the bid-ask mid-point returns. All weather variables are deseasonalized by subtracting its average value of each calendar week (Hirshleifer and Shumway, 2003). They regress stock returns and each trading variable on cloud cover, while controlling for other adverse weather conditions such as snowiness, raininess, temperature and wind speed. They show that cloudiness has a significant influence on stock returns, only at the market open, a significant positive effect on intraday volatility and a negative effect with market depth over the entire trading day.

Note 4. Kamstra et al. (2000) examine the empirical association between daylight savings time (DST) and stock market returns. They use stock market data from the US, Canada, UK and Germany from 1928 to 1998 and calculate the mean of daily returns following a DST shift in fall and spring, a weekend and on all other normal days. They find that the 
magnitude of the DST to be roughly 200 to 500 percent of the regular weekend effect, which is both statistically and economically significant.

Note 5. Kamstra et al. (2003) are the first to examine the seasonal affective disorder (SAD) on stock market returns with data from ten countries from 1928 to 2000 . The authors assume that longer nights should be associated with lower stock returns due to the SAD effect or "winter blues", since depression caused by longer nights leads to higher risk aversion. The SAD measure is calculated as the number of hours of night during fall and winter at each stock exchange. They regress returns on up two lagged returns, a Monday dummy, a dummy variable for a tax-loss selling effect, the SAD measure, a fall dummy and three control weather variables (cloud cover, precipitation and temperature). Their evidence suggests the existence of an important effect of SAD on stock market returns that is confirmed for many international markets. In the same framework, Garrett et al. (2005) provide evidence from six stock markets that the SAD effect has full power only if the model incorporates market risk as well as a time-varying price of risk, implying that the SAD effect is a natural consequence of changes in risk aversion over time.

Note 6. Cao and Wei (2005) investigate the relationship between temperature and stock market returns using data from eight financial markets located in the US, Canada, UK, Germany, Sweden, Australia, Japan and Taiwan from 1962 to 2001. The rationale of their research is that temperature affects human behavior, since extreme temperatures may lead to aggression and more specifically high temperatures can also lead to apathy. They test the hypothesis that lower temperatures are associated with higher stock returns due to aggressive risk taking and higher temperatures can lead to higher or lower stock returns, depending on which mood, aggression (risk-taking) or apathy (risk avoidance) dominates. They follow the methodology of Saunders (1993) by grouping returns according to temperature ordering and Hirshleifer and Shumway (2003) and Kamstra et al. (2003) by performing regression analysis to quantify the precise linkage between the two variables, while controlling for other known market anomalies. They find that a statistically significant, overall negative correlation exists between temperature and stock returns, while this relationship is slightly weaker in the summer than in the winter. Their findings remain robust even after controlling for the geographical dispersion of investors relative to the city where the stock exchange.

Note 7. Floros (2008) re-examines the empirical link between temperature and stock market returns using a data sample from Europe (Austria, Belgium, France, Greece and UK) from 1995 to 2005 . He extends previous literature by using a GARCH model and finds a negative relationship between temperature and stock market returns for Austria, Belgium and France, in line with the findings of Cao and Wei (2005).

Note 8. Kang et al. (2010) examine the relationship between stock market returns and volatility and three specific weather variables (temperature, humidity, and sunshine) using the Shanghai A- and B-share indices and daily data from 1996 to 2007. They follow the methodology of Yoon and Kang (2009) and convert the three weather variables into dummy variables, because they contain a seasonal factor, by using the 21-day and 31-day moving average and moving standard deviation. They regress the daily return of the two indices against dummy variables for know calendar anomalies and dummy variables for weather conditions and weather interaction effects. Furthermore, they use a simple GARCH model to capture time-varying volatility. They find that weather has an effect on the returns and volatility of the Shanghai stock market, indicating that various weather conditions affect investor's decisions making.

Note 9. Dichev and Janes (2001) examine if lunar phases affect stock returns, stock returns volatility and trading activity for 25 different countries and a time period of 100 years for the US and 30 years for all other countries. They find that returns around new moon dates are about double the returns around full moon dates. The difference in returns is large and in most cases it exceeds the market risk premium. However, they fail to find evidence indicating a relationship between lunar phases and return volatility or trading activity. Keef and Khaled (2011) also investigate the impact of new and full moons on stock returns through the methodology of panel data and under the present of certain stock market anomalies. They find that only the new moon effect is present.

Note 10. Yuan et al. (2006) also investigate the relationship between lunar phases and stock market returns of 48 countries globally from 1973 to 2001. They follow the evidence and argument in Hirshleifer and Shumway (2003) that good mood is associated with high asset returns. Their methodology involves first the calculation of stock returns in full moon and new moon phases. A sinusoidal model is also estimated to test for the cyclical pattern of the lunar effect and a pooled regression is estimated with panel corrected standard errors for all 48 countries and three subgroups. Finally, they examine if the effect on stock returns is related to stock size. Their findings indicate that stock returns are lower on the days around a full moon than on the days around a new moon. The return difference is statistically and economic significant and is not due to changes in stock market volatility, trading volumes, announcements of macroeconomic indicators, major global shocks, other calendar-related anomalies such as the January effect, the day-of-week effect, the calendar month effect, and the holiday effect (including lunar holidays). 
Note 11. Dowling and Lucey (2008) examine the empirical effect of seven mood-proxies (SAD, DST, Wind, Temperature, Precipitation, Lunar Phases, Geomagnetic storms) on both the returns and variances of 37 national equity market indices and 21 small capitalization indices. Their methodology involves GARCH-type processes to approximate and model the variations in the conditional variance of returns. They show that SAD has the most significant relationship with both equity returns and volatility and that this relationship is more significant for countries furthest from the equator and for small capitalization stocks. For all other mood measures there is at best a weak relationship between them and equity returns and variance.

Note 12. Kaplanski and Levy (2009) consider the effect of SAD and temperature on the VIX option's implied volatility index (Fear Index), which is traded in the Chicago Board Options Exchange (CBOE) and measure the perceived risk of investors. They use also a measure of so-called 'actual' volatility, based on the historical standard deviation of a monthly window of daily returns. Their empirical findings show that the number of daylight hours is negatively related only to the 'perceived' volatility proxied by the VIX and not to the 'actual' historical volatility measure, while temperature is positively correlated to the perceived risk of investors.

Note 13. Symeonides et al. (2010) investigate the empirical association between stock market volatility, in all three forms (historical, implied and realized), and investor mood-proxies, related to the weather and the environment. These are sky cover, temperature, precipitation and the variation in the number of hours of night, i.e. seasonal affective disorder (SAD). They consider the effect of absolute deviations from seasonal norms and of dummies which reflect extreme weather conditions. They use an ARCH-type model on the dataset of Hirshleifer and Shumway (2003), which consists of stock market index returns for 26 stock exchanges internationally between 1982 and 1997, for the historical volatility effects. The implied volatility is proxied by four implied volatility indices for the CBOE along with the term structure of the VIX volatility index, whereas, the realized volatility is constructed on the basis of high-frequency returns for the S\&P500 index. Their results suggest that SAD and cloudiness are negatively associated with various measures of stock market volatility and that the effect depends on the location of a city on Earth with respect to the equator. Finally, their evidence did not show any explanatory power of absolute deviations of variables from seasonal norms and dummies related to extreme weather conditions.

Note 14. Kramer and Runde (1997) replicate the study of Saunders (1993), using data from the Frankfurt stock exchange from 1960 to 1990 and as weather variables cloud cover, relative humidity and atmospheric pressure. They find both a positive and negative effect of weather on stock returns depending upon the test procedure adopted, indicating that short-term stock returns are not affected by local weather.

Note 15. Pardo and Valor (2003) investigate the relationship between sunshine hours and humidity levels and market index returns with the use of data from Spain from 1981 to 2000. The daily returns of the stock index are separated into sunshine hours and relative humidity quintiles. The research hypothesis is tested both on an open outcry trading system and a screen traded environment. Their evidence indicates that, independently of the trading system, there is no influence of weather on stock prices.

Note 16. Tufan and Hamarat (2004) find that weather conditions do not have any effect on stock prices. Specifically, they examine the relationship between cloud cover and the return of the Turkish stock exchange index from 1987 to 2002. In contrast to other studies, they apply the Kruskal Wallis test at quintiles formed on cloudiness.

Note 17. Goetzmann and Zhu (2005) use a large panel database of individual investor accounts from 6 major cities of the US from 1991 to 1995, instead of aggregate market data, to examine if emotion influences decision-making. They calculate the daily cloudiness in a manner similar to Hirshleifer and Shumway (2001) and buy and sell imbalance (BSI), in a way similar to Hong and Kumar (2002) and Zhu (2002). They regress the cloudiness measure against the BSI and total trading volume. They find no difference in the propensity to buy or sell equities on cloudy days as opposed to sunny days. Furthermore, they find that the bid-ask spread widens on cloudy days and when they control for this effect the weather variable becomes smaller and insignificant.

Note 18. Jacobsen and Marquering (2008) use monthly returns on the value weighted indices of Morgan Stanley Capital International (MSCI) representing 48 different countries from 1970 to 2004 to re-examine the relationship between SAD, temperature and stock returns identified by Kamstra et al. (2003) and Cao et al. (2005). They find a strong relationship with summer-winter seasonality in stock returns which, however, cannot be linked directly to weather induced mood changes of investors. They identify other variables that can explain this seasonality, such as the Sell in May/Halloween variable. Their empirical evidence shows that the weather variables are highly correlated with seasons, thus, it is hard to distinguish among them when trying to identify the weather variable/s that explains better stock returns. Finally, they show that seasonal effect is robust to different specifications, estimation techniques and addition of control variables. 
Note 19. Yoon and Kang (2009) examine the relationship between stock returns and volatility and temperature, humidity, and cloud cover for the Korean stock market from 1990 to 2006 . Furthermore, they examine whether the extent of a weather effect may have been weakened following the October 1997 financial crisis. The weather variables are converted into dummy variables and used in a linear regression model using the GJR-GARCH process in error terms. The interaction effects of the weather variables are also considered. They show that before the crisis, extremely low temperatures exerted a positive influence on returns, whereas extremely high humidity and heavy cloudiness exerted a negative effect on returns. However, after the 1997 financial crisis, evidence for a weather effect became insignificant. Finally, the conditional volatility of the Korean stock market tends to be higher when the news is unfavorable. 


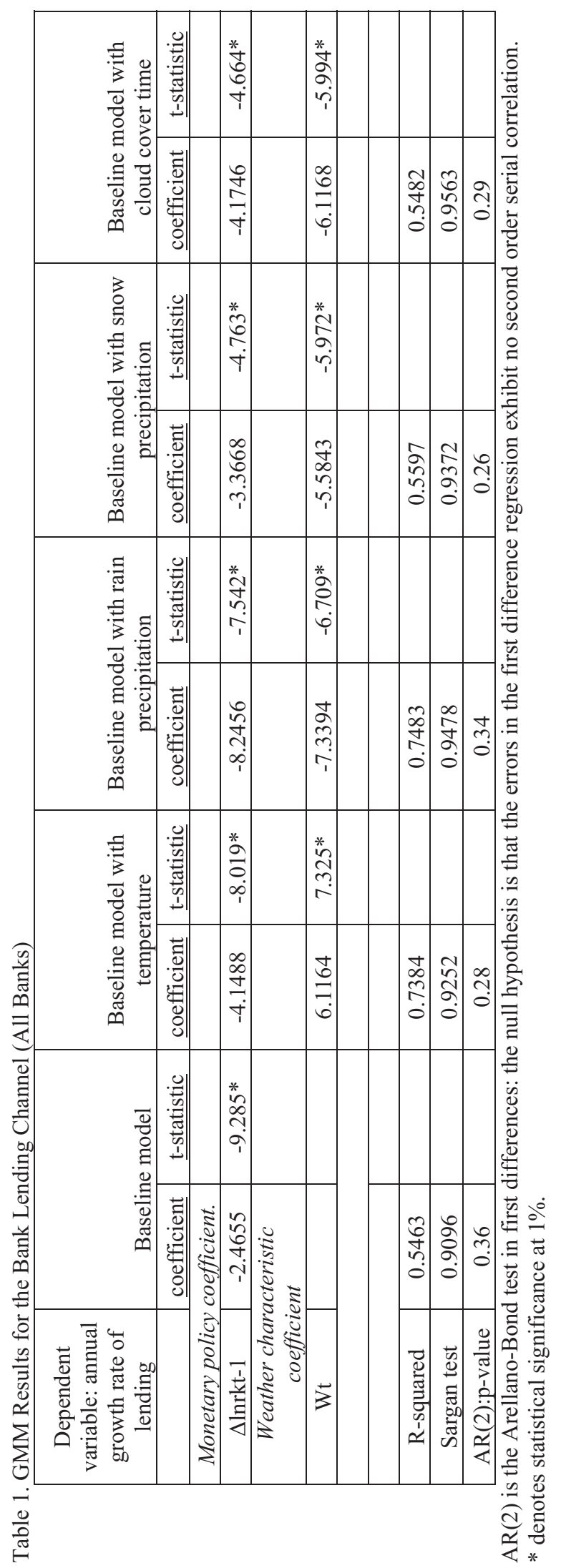




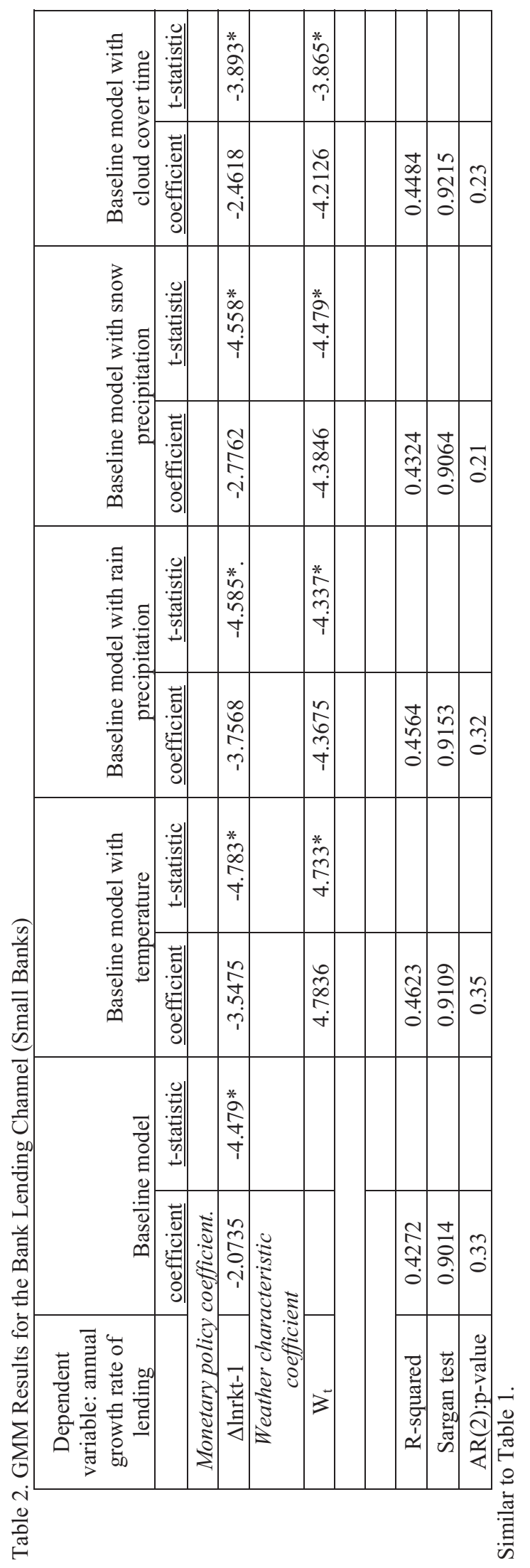




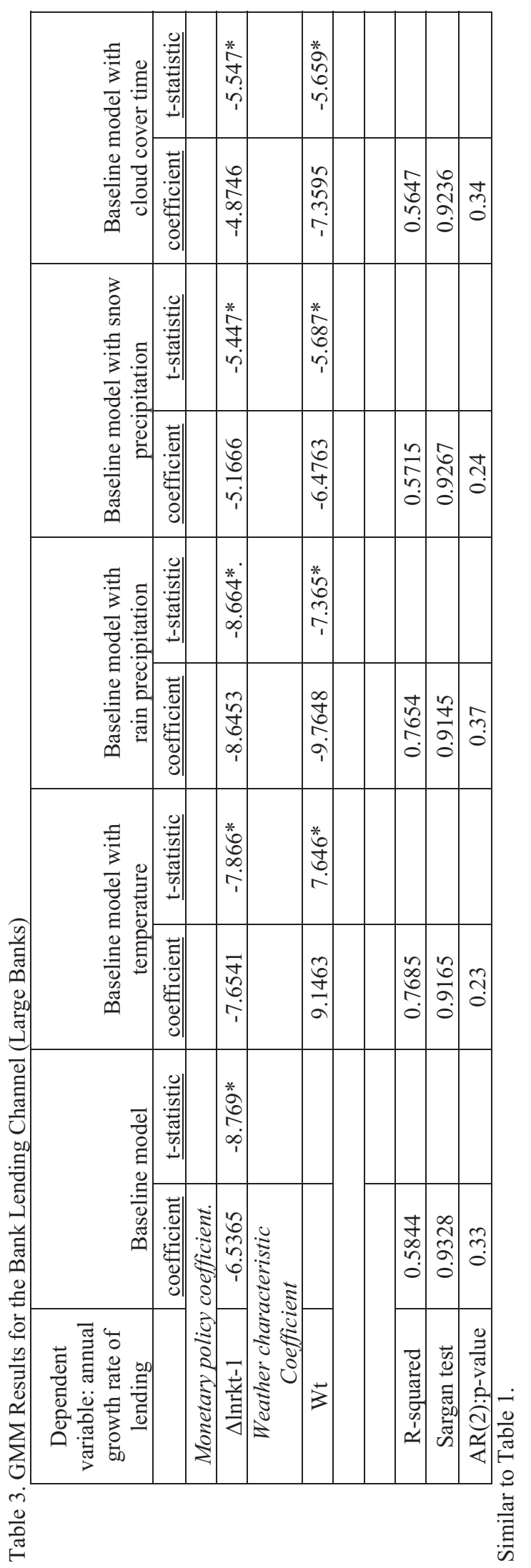

